\title{
Experimental investigation of a heat pipe heat exchanger for heat recovery
}

\author{
Anna Bryszewska-Mazurek, ${ }^{1,}$ Wojciech Mazurek \\ Wroclaw University of Science and Technology, Faculty of Environmental Engineering, 50-370 \\ Wroclaw, Wyspianskiego 27, Poland
}

\begin{abstract}
An air-to-air heat pipe heat exchanger has been designed, constructed and tested. Gravity-assisted wickless heat pipes (thermosiphons) were used to transfer heat from one air stream to another air stream, with a low temperature difference. A thermosiphon heat exchanger has its evaporation zone below the condensation zone. Heat pipes allow keeping a more uniform temperature in the heat transfer area. The heat exchanger consists of 20 copper tubes with circular copper fins on their outer surface. The tubes were arranged in a row and the air passed across the pipes. R245fa was used as a working fluid in the thermosiphons. Each heat pipe had a $40 \mathrm{~cm}$ evaporation section, a $20 \mathrm{~cm}$ adiabatic section and a $40 \mathrm{~cm}$ condensation section. The thermosiphon heat exchanger has been tested in different conditions of air stream parameters (flows, temperatures and humidity). The air face velocity ranged from $1,0 \mathrm{~m} / \mathrm{s}$ to $4,0 \mathrm{~m} / \mathrm{s}$. The maximum thermal efficiency of the thermosiphon heat exchanger was between $26 \div 40 \%$, depending on the air velocity. The freezing of moisture from indoor air was observed when the cold air temperature was below $13^{\circ} \mathrm{C}$.
\end{abstract}

\section{Introduction}

Heat pipe heat exchangers (HPHEs) are used as an efficient air-to-air heat recovery device in many applications. The HPHE provides the separation of hot and cold flows which is essential for heat recovery systems in hospitals, laboratories and other places where a high quality of indoor air is needed [1]. The HPHEs also have high heat recovery effectiveness, no moving parts and a small pressure drop on the air side. It is also possible to independently adjust the heat transfer surface area on the hot and cold sides. One of the most important applications of HPHEs is the heat recovery from exhaust gases [2, 3]. In HPHEs, different kinds of pipes could be used: conventional heat pipe (CHP), two-phase closed thermosiphon (TPCT) and oscillating heat pipe (OHP). In this paper we focused on the two-phase closed thermosiphon (TPCT) which is a heat pipe without the wick structure inside the pipe's inner

\footnotetext{
${ }^{1}$ Corresponding author: anna.bryszewska-mazurek@pwr.edu.pl
} 
wall. For this reason, TPCTs have a simpler construction and are cheaper then CHPs. However, the evaporator section must be situated below the condenser section. The working fluid evaporates in the evaporator section, vapor flows through the adiabatic section to the condenser end, then vapor condenses in the condenser section and flows back gravitationally to the evaporator section. When finned thermosiphons are applied to an air-to-air heat exchanger, they can increase its effectiveness by reducing the temperature difference needed to transfer the heat between air streams.

The aim of this work is to rate the use of HPHE in the heat recovery of exhaust heat from an air conditioning system utilizing gravity assisted two-phase closed thermosiphons. HPHEs in heating, ventilation and air conditioning (HVAC) systems recover heat from exhaust air in cold climates and recover coolness from the exhaust air in hot climates. In this work we focus on heat recovery during the winter season. Most of the publications concern the utilization of HPHEs in HVAC systems for coolness recovery or as air dryers [4, 5]. In most cases CHPs having a wick structure inside the pipe were considered.

The working fluid has a significant impact on the operation of a heat pipe. This fluid could be suitable for the heat flux and temperature range of the heat carriers exchanging heat. In an HVAC system heat is recovered from exhaust air, the temperature of which rarely exceeds $20^{\circ} \mathrm{C}$ and the fresh air temperature is often below $0^{\circ} \mathrm{C}$. In such conditions not only water, but some other working fluids could be taken into account, especially refrigerants. In many applications, CHPs and TPCTs water is used as a working fluid in heat pipes [6,7], but these solutions are proper for temperatures higher than $40^{\circ} \mathrm{C}$. There are some papers that present HPHE with heat pipes filled with other fluids like R11 [8], R134a [9, 10], R410a, R407c, R22 [10]. Refrigerants have a smaller latent heat and a smaller specific heat than water. The saturation pressure of refrigerants is higher than the saturation pressure of water, which causes a higher heat transfer coefficient during the phase change inside the pipe.

\section{Heat pipe heat exchanger}

The thermosiphon heat exchanger consisted of 20 copper tubes that were $1.0 \mathrm{~m}$ long, and had a $10 \mathrm{~mm}$ inside diameter and a $12 \mathrm{~mm}$ outside diameter. The tubes were arranged in one row. On the top of each tube was a valve for the purging of non-condensable gases. The tubes were placed next to each other in a way that their fins made contact. The evaporator and condenser sections of the thermosiphon heat exchanger had a length of $0,4 \mathrm{~m}$ and its central adiabatic section had a length of $0,2 \mathrm{~m}$. The thermosiphon heat exchanger had 300 copper fins per meter, each with a thickness of $0,5 \mathrm{~mm}$ (Fig. 1). These cylindrical cross fins required the air flow in a direction perpendicular to the pipe axis. Gravity-assisted wickless heat pipes operate most effectively when in a vertical position, therefore the evaporation section is below the condenser section.

Refrigerant R245fa was used as the working fluid with a fill ratio of $80 \%$ of the evaporator section length. Based on previous personal research, the optimum filling ratio was established for this pipe dimension and the selected working fluid. The optimum filling ratio of R245fa refrigerant was investigated by comparing the overall thermal resistance obtained for the thermosiphon at a various filling ratio.

One of the goals of the study was also testing the R245fa refrigerant as a working fluid in a thermosiphon, when the operating temperatures are in a range of $0 \div 20^{\circ} \mathrm{C}$. R245fa has a normal boiling point at a temperature of about $15^{\circ} \mathrm{C}$. Within the assumed operating temperature range the saturated pressure inside the pipe was in the range of $48 \div 122 \mathrm{kPa}$. Compared to water, R245fa has a fairly low heat of vaporization $200 \mathrm{~kJ} / \mathrm{kg}$. The relatively high saturated pressure and low latent heat are desirable for obtaining a large heat transfer coefficients inside the pipe. 
It should be noted that R245fa refrigerant will be withdrawn from use in a few years because of its high global warming potential $(\mathrm{GWP}=1030)$. However, there are good alternatives for R245fa, having closer and even better thermodynamic parameters. They are additionally non-flammable and they have very low GWP $($ GWP $<5)$. One that has shown much interest is definitely $\mathrm{R} 1336 \mathrm{mzz}(\mathrm{E})$, which has $\mathrm{GWP}=2$. This refrigerant has its vapor pressure about $20 \%$ higher than R245fa and it has a slightly lower latent heat, which is a benefit in low temperature heat transfer processes.

\section{1 row $=20$ heat pipes}
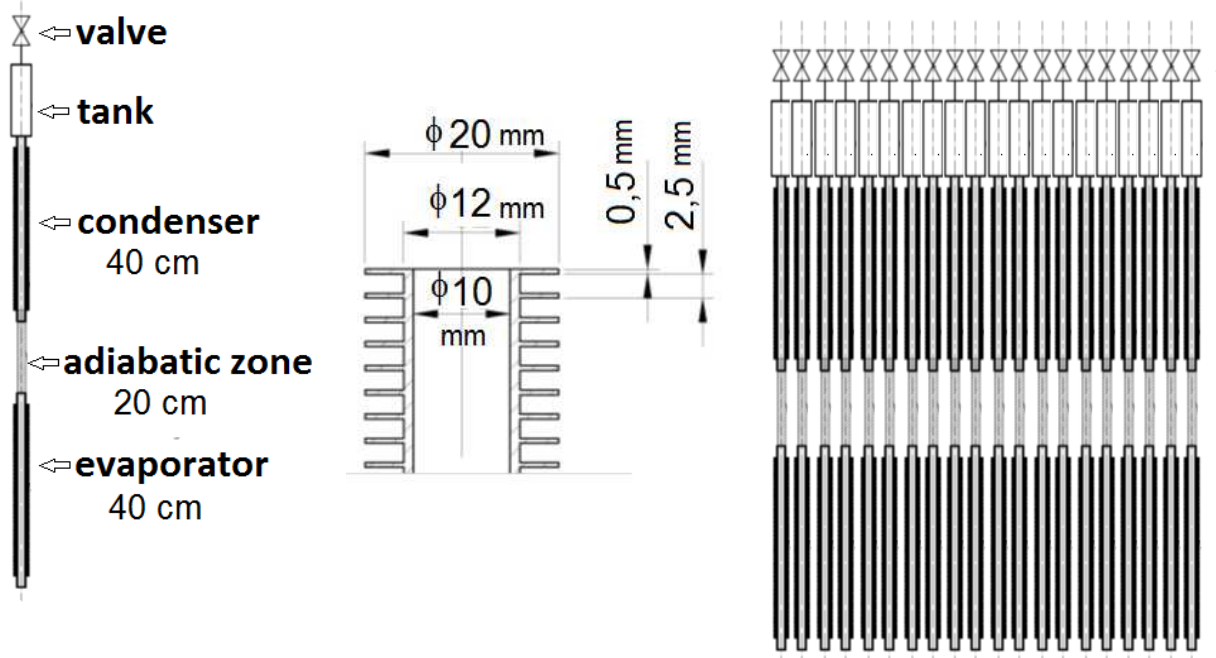

Fig. 1. The thermosiphon heat pipe with characteristic dimensions of fins. The HPHE consists of 20 thermosiphons in one row bank.

\section{Experimental investigations of heat pipe heat exchanger}

In order to study the thermal performance of the thermosiphon heat exchanger, a special test rig was constructed and setup. The schematic diagram of the test rig is shown in Fig.2. The heat exchanger was placed in the test installation, where a countercurrent air flow was forced across the condenser and evaporator section. The inlet temperatures and air flows were controlled independently in the condenser section (simulating fresh air parameters) and in the condenser section (simulating exhaust air parameters). The dimensions of both air ducts connected to the heat exchanger were $400 \times 400 \mathrm{~mm}$. Heat recovery was realized between the exhaust and fresh air.

The inlet temperature and the air flow in the condenser section was controlled through the air water cooler and the regulation and measuring system consists of a fan driven by a variable speed motor, flow measurement orifices, dampers, pressure and temperature sensors (thermocouples and differential pressure transmitters).

The inlet temperature and the air flow in the evaporator section was controlled through the electric heater and the regulation and measuring system consists of a fan driven by a variable speed motor, flow measurement orifices, dampers, pressure and temperature sensors (thermocouples and differential pressure transmitters). Additionally, the steam humidifier and humidity sensor ensured the control, monitoring and simulation of exhaust air inlet humidity. 
The experiments were carried out in stable conditions i.e. set both air flows and inlet temperatures in the hot side (evaporator section) and in the cold side (condenser section). Conditions of experiments:

- both hot and cold air flow have the same value

- air flows were selected to get the set up average inlet air velocities $(1 \div 4 \mathrm{~m} / \mathrm{s})$

- inlet fresh air temperatures was changed in a range of $-15 \div 15^{\circ} \mathrm{C}$

- inlet exhaust air temperature was fixed at $20^{\circ} \mathrm{C}$

For fixed air flows, the inlet fresh air temperature was changed and the heat exchanger performance was analyzed.

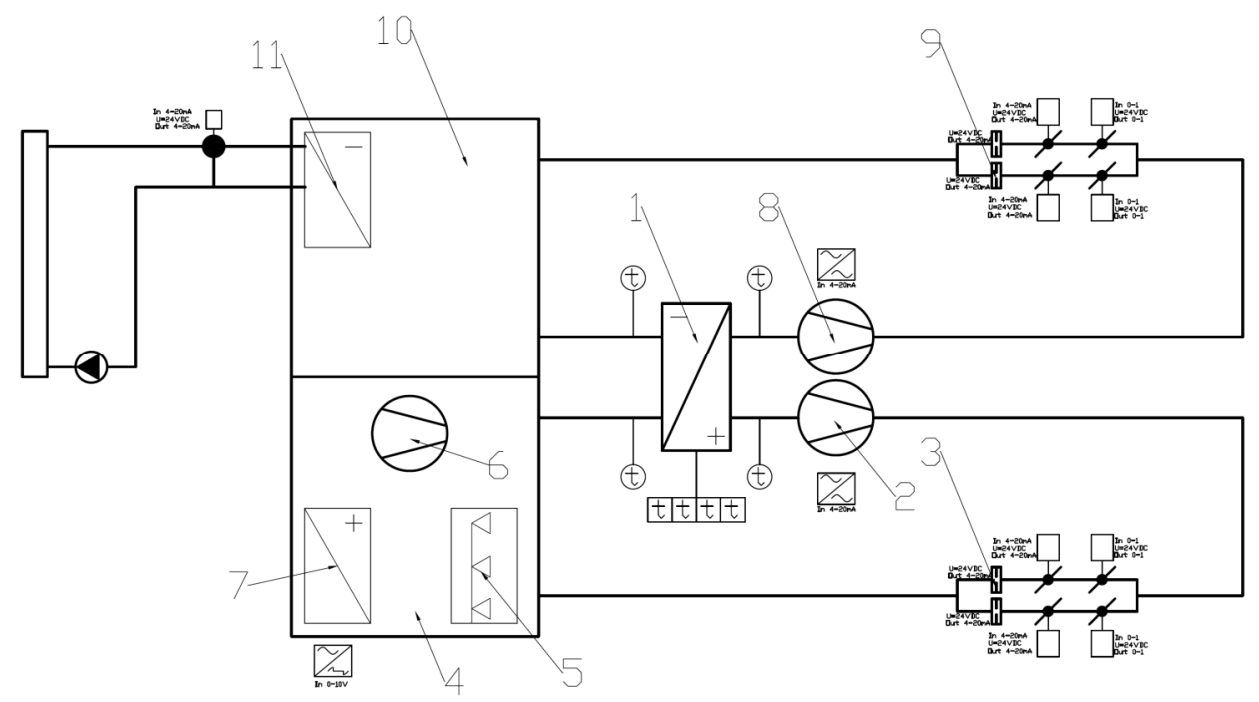

Fig. 2. The test rig: 1- heat pipe heat exchanger, 2- fan (evaporator section), 3- regulation and measuring system for evaporator section, 4- heat insulated chamber, 5-steam humidifier, 6- air mixing fan, 7- electric heater, 8- fan (condenser section), 9- regulation and measuring system for the condenser section, 10- heat insulated chamber, 11- air cooler.

The effectiveness of the recovery heat exchanger could be defined as s ratio of the heat transfer rate of the exchanger to the maximum possible heat transfer between the air streams. Taking into account similar mass flow rates and the specific heat transfer of both air streams (when no water condensation occurs), the effectiveness could be calculated based on air streams temperatures according to the equation (1):

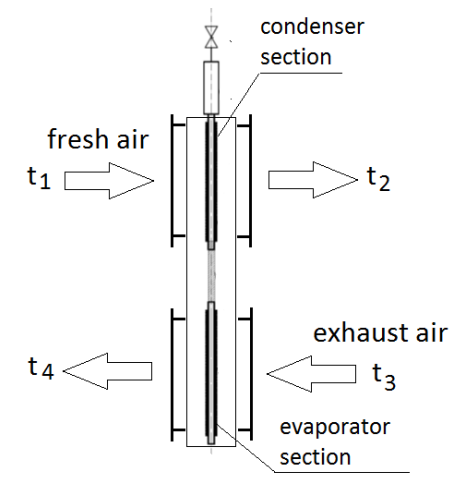

Heat recovery efficiency (condenser section):

$$
\varepsilon=\frac{t_{2}-t_{1}}{t_{3}-t_{1}}
$$

Fig. 3. Schematic of the flow arrangement and corresponding parameters. 
The effectiveness of the heat pipe heat exchanger was calculated from air temperatures measured in both the inlet and in the outlet of heat exchanger. An average air velocity was obtained on the basis of the air flow and air duct dimensions. The effectiveness of the heat pipe heat exchanger in the function of the air temperature difference between the evaporator inlet and the condenser inlet is presented in Fig. 4. The efficiency changes in the range of $5 \div 40 \%$, depending on the temperature difference between the evaporation and condensation sections. The heat pipe heat exchanger achieves the highest efficiency when the fresh air temperature is the lowest. At the same time, the air face velocity has a strong impact on the efficiency, which has been shown in Fig.4 and Fig. 5. As the air face velocity increases, the efficiency decreases and this effect is stronger when the temperature difference of the inlet air flows is large.

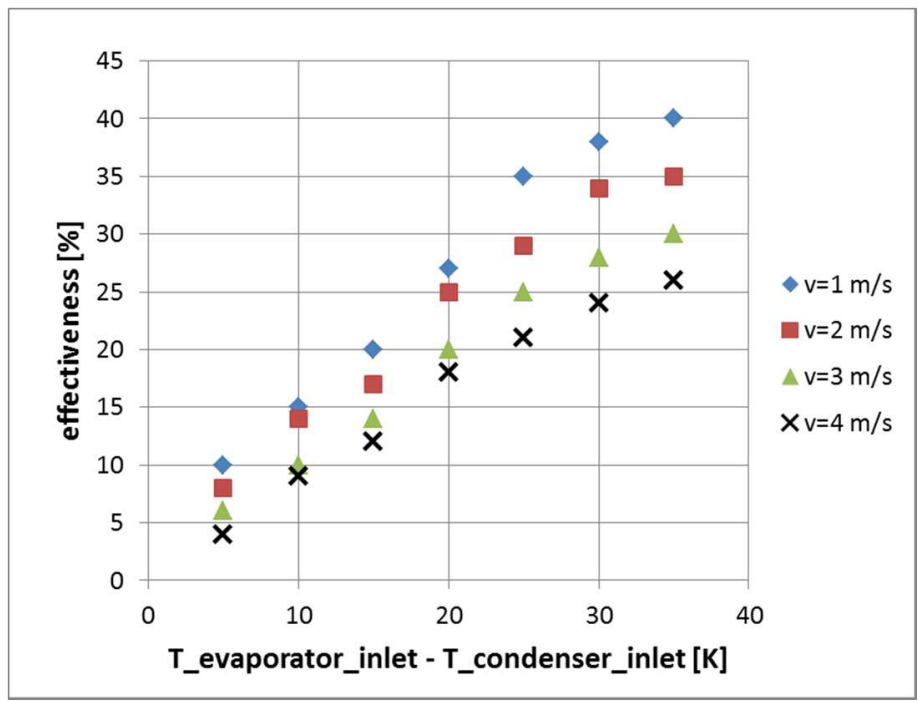

Fig. 4. Effectiveness of the heat pipe heat exchanger versus the air temperature difference between the evaporator inlet and the condenser inlet.

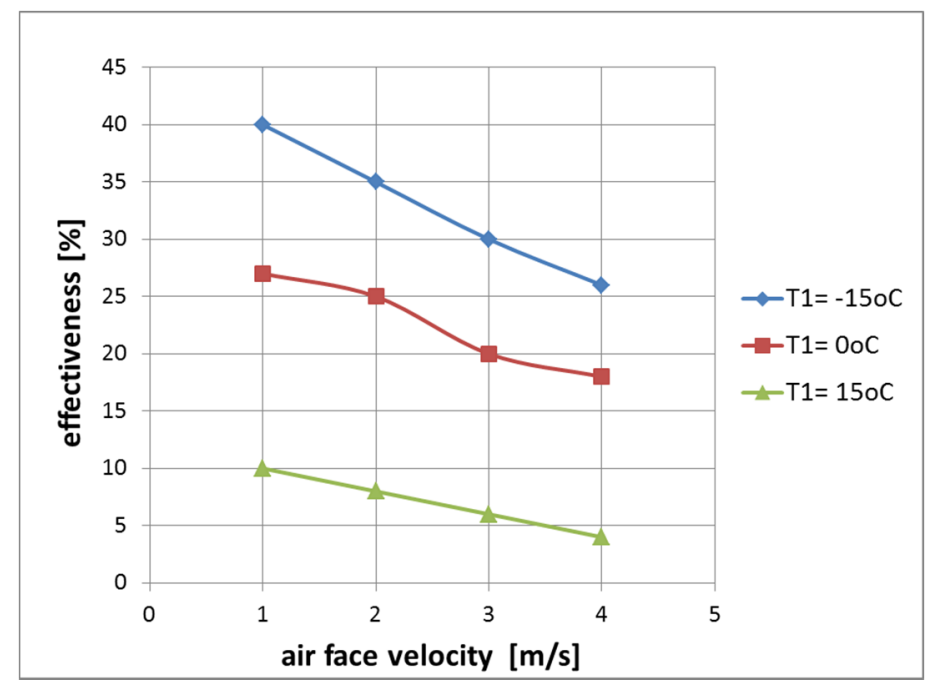

Fig. 5. Effectiveness of the heat pipe heat exchanger versus average air face velocity. ( $T_{1}-$ air inlet temperature in the condensation section). 


\section{Conclusions}

The thermosiphon heat exchanger was designed, constructed an experimentally tested. The two-phase closed thermosiphons working with R245fa refrigerant were used to build one row heat exchanger. Thermal performance investigations of this air-to-air HPHE were carried out. The heat recovery process between the hot and cold air streams simulates the heat recovery between exhaust and fresh air streams in an HVSC system.

The temperature of the hot air was fixed at $20^{\circ} \mathrm{C}$ and the cold air temperature was changed in a range of $-15 \div 15^{\circ} \mathrm{C}$. The effectiveness of the heat-pipe heat recovery was determined for the steady air flows through the evaporation and condensation section in the HPHE. The air flow in the range of $570 \div 2300 \mathrm{~m}^{3} / \mathrm{h}$ corresponded to the assumed air face velocities in the range of $1 \div 4 \mathrm{~m} / \mathrm{s}$.

The effectiveness of heat-pipe heat recovery changes in a range of $5 \div 40 \%$, and is dependent on the temperature difference between the evaporation and condensation sections. The maximum effectiveness was for the lowest inlet air temperature of the cold flow. The experimental measurements show that air velocity has a significant effect on the effectiveness of heat-pipe heat recovery. The effectiveness decreases with increasing air velocity.

The relatively low effectiveness of heat-pipe heat recovery is connected with the rather low temperature difference between air streams $(5 \div 35 \mathrm{~K})$ and the low heat transfer coefficients on the air side (about $25 \div 38 \mathrm{~W} /\left(\mathrm{m}^{2} \mathrm{~K}\right)$ ).

When the fresh air temperature is below $0^{\circ} \mathrm{C}$ and the exhaust air contains a large amount of humidity, a freezing effect on the condenser section could occur. Heat pipes provide stability, usually above $0^{\circ} \mathrm{C}$ temperatures on the tube's wall. This temperature is close to the average temperature of the cold and hot air flow in the HPHE. Freezing was observed during the experiments, when the cold air temperature was below $-13^{\circ} \mathrm{C}$ and the relative humidity of the exhaust air was above $80 \%$. The effect of moisture freezing was detected by measuring the differential pressure for the air flows in the heat exchanger. A sudden rise in air flow resistance indicates the freezing of moisture.

Heat pipe heat exchangers don't meet the requirements of Eco-design directive because of their extremely low efficiency. This also applies to all kinds of heat exchangers with intermediate fluid.

Heat pipe heat exchangers may be applied in a situation where fluids exchanging heat shouldn't make contact with people due to the risk of contamination. Such situations take place in hospitals or in industrial applications as exhaust air or gases could be contaminated. It should be emphasized that in conditions of high humidity of exhaust air and a low outside temperature, if frost occurs, the efficiency of the heat exchanger drastically decreases. This problem concerns many heat exchangers meeting the Eco-design requirements, it especially concerns highly efficient heat exchangers. Heat pipe heat exchangers show high resistance to freezing even for high humidity exhaust air, so their total annual efficiency could be better than other heat exchangers.

The work was founded by the National Science Centre (Poland);

Research project no N N523 561138: A recuperator made of self-regulating heat pipes

\section{References}

1. N. Putra, T. Anggoro, A. Winatra, Int. J. Adv. Sci. Eng. Inf. Tech., 7, 871 (2017)

2. L. Vasiliev, Appl. Therm. Eng., 25, 1 (2005)

3. W. Srimuang, P. Amatachaya, Ren. \& Sust. En. Rev., 16, 4303 (2012)

4. Y.H. Yau, Int. J. Therm. Sci, 46, 164 (2007) 
5. Y.H. Yau, M. Ahmadzadehtalatapeh, Appl. Therm. Eng. 30, 77 (2010)

6. S.H. Noie, App. Therm. Eng., 26, 559 (2006)

7. H. Jouhara, H. Merchant, Energy, 39, 82 (2012)

8. M.A. Abd-Baky, M.M. Mohamed, Appl. Therm. Eng. 27, 795 (2007)

9. T. Sukchana, N. Pratinthong, Exp. Therm. \& Flu. Sci. 77, 317 (2016)

10. M.A.M. Hassan, J. En. Eng., 139, 18 (2013) 